\title{
Diffusion Bonding of Magnesium Alloy (AZ31B) to Cu by Using Sn Foil Interlayer
}

\author{
Shuang-Ming $\mathrm{DU}^{\mathrm{a}}$, Jie $\mathrm{HU}^{\mathrm{b}}$
}

College of Materials Science and Engineering, Xi'an University of Science and Technology, Xi'an 710054, China

ashuangmingdu@163.com, ${ }^{\mathrm{b}} \mathrm{clhujie2009@163.com}$

Keywords: Diffusion Bonding, Sn Foil, AZ31B/Cu, Microstructure.

\begin{abstract}
The experimental investigation of diffusion bonding of magnesium alloy (AZ31B) to $\mathrm{Cu}$ in vacuum was carried out by using Sn foil as transition metal. The microstructure of the welded joints was studied by SEM, EDS, XRD and the mechanical properties of the samples were tested by tensile experiments. The results show that: the microstructure at interface zone of diffusion brazing joint includes $\gamma-\mathrm{Cu}, \mathrm{Mg}_{2} \mathrm{Sn}, \mathrm{Mg}-\mathrm{Sn}-\mathrm{Cu}$ ternary intermetallic compounds, $\mathrm{Mg}_{17}(\mathrm{Cu}, \mathrm{Al})_{12}$ and $\left(\alpha-\mathrm{Mg}+\mathrm{Mg}_{2} \mathrm{Sn}\right)$ eutectic structure, and the width of diffusion zone increased with the extension of the holding time, the maximum can reach up to $400 \mu \mathrm{m}$ under the condition of $420{ }^{\circ} \mathrm{C}, 90 \mathrm{~min}$. The hardness of diffusion welding area was significantly higher than the substrate.
\end{abstract}

\section{Introduction}

In recent years, due to the rapid development of electronic products, especially the high-power LED products, its packaging materials put forward higher requirements on thermal conductivity and heat dissipation. Magnesium alloy has low density, high specific stiffness and strength, good thermal conductivity, especially excellent heat resistance, and copper has good thermal conductivity [1-4]. In order to make full use of their advantages and meet the market demand of high-power electronics cooling products, it is necessary to develop a composite metal material which not only maintain the high thermal conductivity of copper, but using the lightweight and high heat dissipation of magnesium. However, the joining together of these dissimilar alloys still presents a challenge and this can be attributed to the considerable differences in their physical and metallurgical properties[5].

Diffusion bonding is an attractive joining technique which enhance the physical contact of surface to be welded by micro plastic deformation and then achieved combination by mutual diffusion of atom. The heating temperature of diffusion bonding is far below the melting point of base metal and it can heat evenly, which would avoids the bad influence of physical and chemistry characters of base metal caused by conventional welding method. And it is fit for connection situation of large area and high dimensional accuracy [6]. Above all, diffusion welding in vacuum has been concerned in bonding dissimilar materials, but because of the low solubility of magnesium and titanium, it will produce series of brittle metal compounds that worsen the structure and mechanical property of welded joint when welding directly [7]. The research literature [8-10] shows that the suitable interlayer can play a positive role in avoiding forming brittle metal compounds among dissimilar metals, it is an important method to improve the quality of diffusion welding joints. In this study, Sn foil has been used as a method of forming a eutectic with the metals of $\mathrm{AZ31B/Cu}$ being joined.

\section{Materials and Experimental}

$2 \mathrm{~mm}$ thickness wrought magnesium alloy AZ31B plate and $2 \mathrm{~mm}$ industry pure copper plate were used as the base materials in the experiment. The interlayer employed in diffusion bonding process was Sn foil with the thickness of $20 \mu \mathrm{m}$. The chemical composition and thermo-physical properties of AZ31B and pure copper are given in tables 1 and 2 .The test materials of AZ31B and pure copper plates were cut by the lining cutting machine with dimension of $60 \mathrm{~mm} \times 40 \mathrm{~mm}$. The 
surfaces of metal to be joined were prepared on SiC paper to a 2000 grift finish and then ultrasonically cleaned with acetone for $5 \mathrm{~min}$. The treated specimens were stacked in a homemade die, and the entire diffusion bonding setup was inserted into a vacuum chamber.

Tab.1 Chemical composition and properties of AZ31B Magnesium alloy

\begin{tabular}{cccccccc}
\hline $\mathrm{Mg}$ & $\mathrm{Al}$ & $\mathrm{Zn}$ & $\mathrm{Mn}$ & $\mathrm{Si}$ & Melting Point $/{ }^{\circ} \mathrm{C}$ & Density $/\left(\mathrm{g} \cdot \mathrm{cm}^{-3}\right)$ & Shear strength/MPa \\
\hline Bal & 3 & 1 & 0.35 & 0.005 & 660 & 1.74 & 140 \\
\hline
\end{tabular}

Tab. 2 Chemical composition and properties of copper

\begin{tabular}{cccccccc}
\hline $\mathrm{Cu}$ & $\mathrm{Fe}$ & $\mathrm{O}$ & $\mathrm{Ni}$ & $\mathrm{Pb}$ & Melting Point $/{ }^{\circ} \mathrm{C}$ & Density $/\left(\mathrm{g} \cdot \mathrm{cm}^{-3}\right)$ & Shear strength $/ \mathrm{MPa}$ \\
\hline 99.9 & 0.005 & 0.06 & 0.006 & 0.005 & 1083 & 8.96 & 150 \\
\hline
\end{tabular}

The process of AZ31B/Cu diffusion bonding is as follows: When the degree of vacuum reached $1 \mathrm{~Pa} \sim 4 \mathrm{~Pa}$, heated work piece from room temperature to $200{ }^{\circ} \mathrm{C}$ with the heating rate of $10{ }^{\circ} \mathrm{C} / \mathrm{min}$ and the degree of vacuum maintained at below $10 \mathrm{~Pa}$. When the temperature is higher than $200^{\circ} \mathrm{C}$, purged argon to the furnace chamber, with a heating rate of $13{ }^{\circ} \mathrm{C} / \mathrm{min}$ until the temperature reaches $420{ }^{\circ} \mathrm{C}$, and then holding time for $60 \mathrm{~min}$. After the incubation, pressure is removed. The bonded samples were allowed to cool down to room temperature inside the bonding chamber and under vacuum atmosphere.

For metallographic examination, the bonded samples were cut transversely through the joint region and polished using diamond suspension down to a $0.5 \mu \mathrm{m}$ finish. Grounded and polished cross sections were etched in reagents $(5 \% \mathrm{HNO} 3)$ for $20 \mathrm{~s}$. Microstructural developments of the joints were examined using scanning electron microscope (S-4800). The chemical compositions of the micro-zones in the joints were analyzed by energy-dispersive X-ray spectroscopy (EDS). Phase structure in the joints were identified using X-ray diffraction (XRD). Microhardness testing of the joints rejoin were conducted using a hardness tester (HVS-50), with a load pressure of $0.25 \mathrm{~N}$ and a holding time of $5 \mathrm{~s}$.

\section{Results and Discussions}

\section{Bond Formation and Microstructural Analysis}

Figure 1 shows optical micrographs of the $\mathrm{AZ31B} / \mathrm{Sn} / \mathrm{Cu}$ bond interfaces after bonding at $420{ }^{\circ} \mathrm{C}$ for 30, 60 and $90 \mathrm{~min}$. It can be noticed that with the extension of holding time, the width of the diffusion zone gradually increased. In the holding time of $30 \mathrm{~min}$, the diffusion region is not obvious. By increasing the bonding time to $60 \mathrm{~min}$, the interlayer and base materials have a fully diffusion resulted in the interlayer $\mathrm{Sn}$ foil disappeared at last, the joint interface region contained lamellar eutectic structure, $\mathrm{Mg}$-Sn solid solution and $\mathrm{Cu}-\mathrm{Sn}$ solid solution compounds. A further increase in the bonding time to $90 \mathrm{~min}$, diffusion of the interlayer and the substrate is more uniform, the width of the diffusion region has reached about $400 \mu \mathrm{m}$.

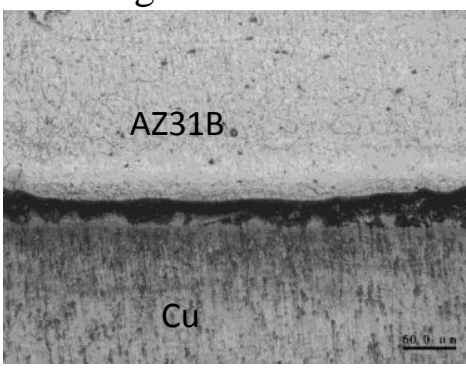

(a) $420{ }^{\circ} \mathrm{C}, 30 \mathrm{~min}$

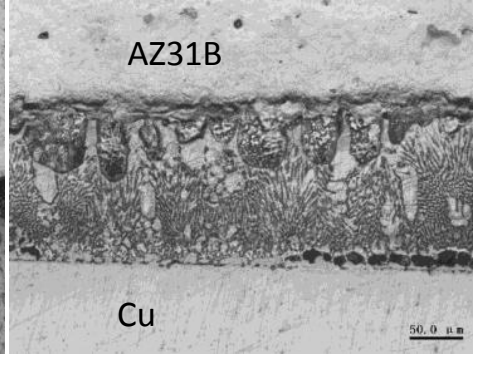

(b) $420{ }^{\circ} \mathrm{C}, 60 \mathrm{~min}$

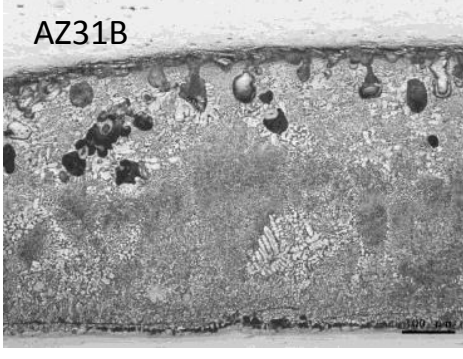

(c) $420{ }^{\circ} \mathrm{C}, 90 \mathrm{~min}$

Fig.1 Microstructure of diffusion brazed joint at different holding time 
According to the $\mathrm{Mg}-\mathrm{Sn}$ binary phase diagram, it can be suggested that holding time at $420{ }^{\circ} \mathrm{C}$, atom interdiffusion of $\mathrm{Sn}$ and $\mathrm{Mg}$ occurred. On one hand, Sn diffuse to the substrate of AZ31B and generated a magnesium-based solid solution towards the surface of AZ31B. The continuous diffusion of $\mathrm{Sn}$ changes the composition until it reached the stabled composition of $\mathrm{Mg}_{2} \mathrm{Sn}$ $(10.7 \mathrm{wt} \%)$. On the other hand, $\mathrm{Mg}$ diffuse to the Sn foil and formed the solid solution on the interlayer surface, it changes to a balanced liquid immediately because of the low solubility of $\mathrm{Mg}$ in $\mathrm{Sn}$. It can be noticed from the $\mathrm{Mg}-\mathrm{Sn}$ binary phase diagram, under the condition of $420{ }^{\circ} \mathrm{C}$, the solubility of $\mathrm{Cu}$ in $\mathrm{Sn}$ is extremely small, almost no, but the solubility of $\mathrm{Sn}$ in $\mathrm{Cu}$ can reach $9 \%$, hence, it mainly occurred the diffusion of $\mathrm{Sn}$ to $\mathrm{Cu}$, a new phase of $\mathrm{Cu}_{3} \mathrm{Sn}$ formed until the composition reached the stabled (9wt \%). With the continuous diffusion, new phase of $\mathrm{Cu}_{6} \mathrm{Sn}_{6}$ generated until the composition of $\mathrm{Sn}$ in copper-based solid solution up to $43.5 \mathrm{wt} \%$.

Figure 2 shows scanning electron micrographs of the $\mathrm{AZ} 31 \mathrm{~B} / \mathrm{Sn} / \mathrm{Cu}$ bond interfaces after bonding at $420{ }^{\circ} \mathrm{C}$ for $60 \mathrm{~min}$. Wherein Figure 2(a) is the cross-section overall morphology of the composite plate. It can be seen from the picture, there are three layers of magnesium matrix, a transition zone and the copper substrate. The joint combined well with the absence of interfacial voids, cracks and other defects. A significant diffusion layer formed between the magnesium alloy and copper, its width is about $70 \mu \mathrm{m}$, the liquid phase has a better bonding with the magnesium alloy than copper, lamellar eutectic appeared near the magnesium side. Figure (b) is an enlarged zone of the welded zone, different regions of the energy spectrum test results shown in Table 3 . The atomic percent ratio of $\mathrm{Mg}: \mathrm{Sn}$ in A region is about 2:1 which represented $\mathrm{Mg}_{2} \mathrm{Sn}$. According to the component ratio of $\mathrm{B}, \mathrm{C}, \mathrm{D}$ and $\mathrm{Mg}-\mathrm{Sn}, \mathrm{Cu}-\mathrm{Sn}$ binary phase diagram, it can be determined the weld area is mainly containedy $-\mathrm{Cu}, \mathrm{Mg}_{2} \mathrm{Sn}, \mathrm{Mg}-\mathrm{Sn}$ - $\mathrm{Cu}$ ternary intermetallic compounds, $\mathrm{Mg}_{17}(\mathrm{Cu}, \mathrm{Al})_{12}$ and $\left(\alpha-\mathrm{Mg}+\mathrm{Mg}_{2} \mathrm{Sn}\right)$ eutectic structure.

Furthermore, formation of the new phases which discussed above can also be explained by XRD analysis across the welded joints. The results show that, on the condition of $420{ }^{\circ} \mathrm{C}, 60 \mathrm{~min}$, the microstructure of $\mathrm{AZ} 31 \mathrm{~B} / \mathrm{Sn} / \mathrm{Cu}$ joint was $\mathrm{Mg}_{2} \mathrm{Sn}, \mathrm{Cu}_{3} \mathrm{Sn}$ intermetallic compounds, $\mathrm{Cu}(\mathrm{Sn})$ and $\mathrm{Mg}$ (Sn) solid solution.

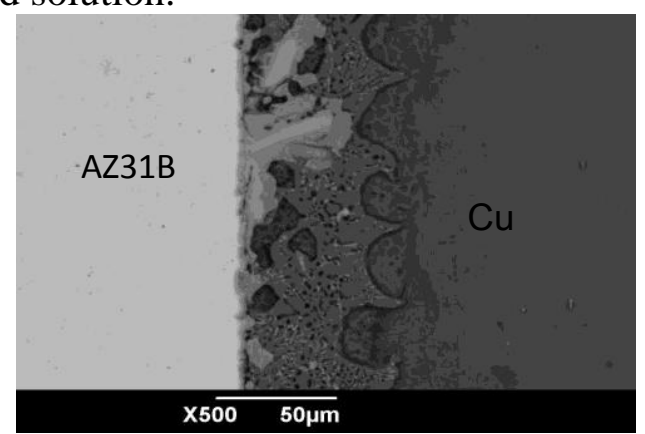

(a)

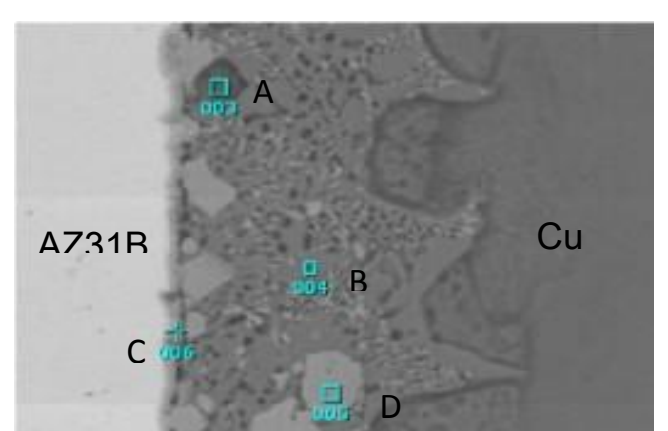

(b)

(a) The cross-section overall morphology of the composite plate (b) an enlarged zone of the welded zone

Fig. 2 Microstructures of interface zone of $420^{\circ} \mathrm{C}, 60 \mathrm{~min}$

Tab.3 The test result of different regions of element composition near the weld zone

\begin{tabular}{cclll}
\hline Element & $\mathrm{A}(\mathrm{At} \%)$ & $\mathrm{B}(\mathrm{At} \%)$ & $\mathrm{C}(\mathrm{At} \%)$ & $\mathrm{D}(\mathrm{At} \%)$ \\
\hline $\mathrm{Mg}$ & 61.04 & 40.51 & 16.86 & 39.56 \\
\hline $\mathrm{Cu}$ & - & 11.66 & 49.19 & 13.19 \\
\hline $\mathrm{Sn}$ & 38.96 & 47.83 & 33.95 & 47.25 \\
\hline
\end{tabular}

\section{Micro-hardness Profile}

Structural characteristics of $\mathrm{AZ31B} / \mathrm{Cu}$ diffusion welding joints determines its mechanical properties. Micro hardness profiles taken across the $\mathrm{AZ31B} / \mathrm{Sn} / \mathrm{Cu}$ joint region are shown in figure 4. It can be seen, copper matrix has a lower micro-hardness value, approximately $80 \mathrm{HV}$, and magnesium matrix microhardness value is about $57 \mathrm{HV}$, while a maximum microhardness of 178 HV was achieved in the diffusion zone, which is about two to three times of matrix structure. This 
can be attributed to the presentence of high hardness intermetallic compounds. On the interface region appeared microhardness increased, which is due to $\alpha-\mathrm{Mg}(\mathrm{Cu})$ solid solution in the magnesium substrate side diffusion layer and precipitation of the second phase, it play an important role in strengthening the interface region, resulting in increased of hardness. $\mathrm{Cu}-\mathrm{Sn}$ interdiffusion occurred towards the copper matrix, the forming of $\mathrm{Cu}(\mathrm{Mg})$ solid solution can strength the joint.

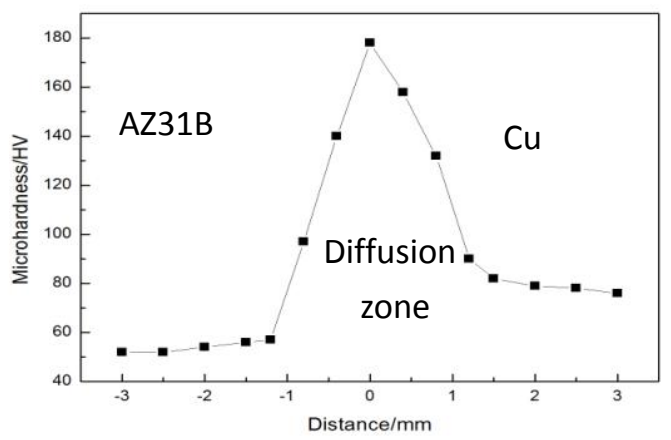

Fig.4 Microhardness distribution of the AZ31B/Sn/Cu welded joint

\section{Conclusion}

Diffusion bonding of magnesium alloy (AZ31B) to $\mathrm{Cu}$ was successfully achieved using Sn foil interlayers. With the extension of the holding time, the width of the joint diffusion region increases, the maximum can reach up to $400 \mu \mathrm{m}$. The interface region of $\mathrm{AZ3} 1 \mathrm{~B} / \mathrm{Sn} / \mathrm{Cu}$ generated $\gamma-\mathrm{Cu}$, $\mathrm{Mg}_{2} \mathrm{Sn}, \mathrm{Mg}-\mathrm{Sn}-\mathrm{Cu}$ ternary intermetallic compounds, $\mathrm{Mg}_{17}(\mathrm{Cu}, \mathrm{Al})_{12}$ and $\left(\alpha-\mathrm{Mg}+\mathrm{Mg}_{2} \mathrm{Sn}\right)$ eutectic structures under the condition of $420{ }^{\circ} \mathrm{C}, 90 \mathrm{~min}$. The hardness of diffusion welding area was significantly higher than the substrate of $\mathrm{AZ31B}, \mathrm{Cu}$, and its hardness range from 90 to $178 \mathrm{HV}$.

\section{References}

[1] Ding Wenjiang. Science and technology of magnesium alloy [M]. Beijing: Science Press, 2007.

[2] Huang Wanqun, Ma Lijun, Wang Xin. Welding of magnesium alloys to other metal alloys [J].Aerospace Materials \& Technology, 2010, (4): 1-4.

[3]Chinese Mechanical Engineering Society Institute of Welding.Welding Handbook (2) Welding materials [M].Bei Jing: Mechanical Industry Press, 2001:608.

[4] American Society of Metals. Metals Handbook [M]. Ninth edition, sixth volumes. Welding, Brazing, Soft brazing .Bei Jing: Mechanical Industry Press, 1994.

[5]Waled M. Elthalabawy. Tahir I. Khan.Eutectic bonding of austenitic stainless steel 316L to magnesium alloy AZ31 using copper interlayer. Int J Adv Manuf Technol(2011)55:235-241.

[6] Fang Hangzhou, Feng Jicai.Material behavior during the connection interface [M]. Harbin: Harbin Institute of Technology Press, 2005.

[7] Liu Peng. Microstructure and element diffusion in welding interface of $\mathrm{Mg} / \mathrm{Al}$ dissimilar metals [D]. Jinan: Shandong University, 2006.

[8] Du Shuangming, Wang Zhihua[M].Welding technology, Beijing Normal University press, 2011.

[9] Wu Ming-fang, Si Naichao, Chen Jian. Contact reactive brazing of Al alloy/Cu/ stainless steel joints and dissolution behaviors of interlayer [J]. Trans. Nonferrous Met.Soc.China, 2011, 21:1 035-1039.

[10] Du shuangming, Liu Gang, Wang Mingjing . Microstructure and properties of transient liquid phase diffusion bonding of AZ31B/Cu of dissimilar metals joint [J]. Chinese Journal of Nonferrous Metals Yuan 2013, (5):1255-1264. 